\title{
Endoscopic removal of intrauterine contraceptive device embedded into detrusor muscle of urinary bladder: our experience of two cases
}

\author{
Ajit Sawant, Gaurav V. Kasat*, Vikash Kumar, Prakash Pawar, \\ Ashwin Tamhankar, Lomesh Kapadnis
}

\begin{abstract}
Department of Urology, Room No 219, College Building, Lokmanya Tilak Municipal Medical College, Sion, Mumbai, Maharashtra, 400022, India
\end{abstract}

Received: 02 October 2015

Accepted: 18 November 2015

\author{
*Correspondence: \\ Dr. Gaurav V. Kasat, \\ E-mail: gauravkasat@gmail.com
}

Copyright: ( $)$ the author(s), publisher and licensee Medip Academy. This is an open-access article distributed under the terms of the Creative Commons Attribution Non-Commercial License, which permits unrestricted non-commercial use, distribution, and reproduction in any medium, provided the original work is properly cited.

\begin{abstract}
Migration of intrauterine contraceptive device (IUD) into urinary bladder is a rare event, presenting as irritative lower urinary tract symptoms; we present two cases of migrated IUD into urinary bladder and embedded inside the detrusor muscle of bladder. Both patients were assessed by ultrasonography and computed tomography. Both patients were successfully treated by endoscopic approach via per urethral route. One patient was having embedded vertical arm of IUD which was pulled using forceps and second patient was having embedded horizontal arm of IUD in detrusor muscle which was treated by taking mucosal incision with help of Collin's knife followed by pulling IUD with help of forceps. There was no evidence of fistula or any other complication. We would like to conclude that endoscopic removal of IUD embedded into detrusor muscle is safe, feasible alternative to open surgery without any further risk of fistula formation.
\end{abstract}

Keywords: Intrauterine contraceptive device, Urinary bladder, Detrusor muscle, Migration, Complication

\section{INTRODUCTION}

As per world contraceptive patterns given by United Nations in 2013, intrauterine contraceptive devices (IUD) are popular mode of contraception in world measuring $13.9 \%$, which accounts for $8.9 \%$ in developed country $\& 14.7 \%$ in developing country. ${ }^{1}$ IUD is well accepted to women due to reversible long term contraception, low complication rate and high effectiveness. Incidence of complications of IUD may be low but are serious such as bleeding, infection, ectopic pregnancy, uterine perforation. Uterine perforation after copper IUD was 2.2 per 1000 IUD insertions and after levonorgestrel releasing intrauterine system is 2.6 per 1000 insertions. $^{2,3}$ But migrated IUD and embedded into detrusor muscle is very rare, migrated IUD in bladder may form stones inside urinary bladder. ${ }^{4}$

\section{CASE REPORT}

We report two cases of migrated IUD into urinary bladder which are embedded into detrusor muscle which successfully managed by endoscopic retrieval of IUD via per urethral route.

Total 2 patients were diagnosed to have migrated IUD from uterus to urinary bladder from 2013 to 2015. Diagnosis was made by doing per abdominal ultrasound and patients were operated by endoscopic removal of IUD under spinal anaesthesia.

In both patients IUD was inserted at other center, both patients were diagnosed after per abdominal ultrasound examination. Table 1 is showing characteristics of both patients and treatment given to them. Both the patients IUD was embedded in bladder wall hence computerized tomography (CT) cystogram was done. Figure 1 is 
showing CT image of the IUD embedded inside detrusor muscle. Figure 2 is showing graphical representation of IUD embedded inside detrusor muscle. After initial diagnosis both patients were treated by endoscopic removal of IUD via per urethral route. Figure 3 is showing cystoscopic view of IUD embedded into detrusor muscle. Nephroscope and assembly were introduced into bladder and with help of stone holding forceps IUD was removed intact. Both patients were discharged after 3-4 days of surgery and catheter was removed after 7 days and 14 days respectively. Injectable antibiotics were given for one day followed by oral antibiotics for 5 days. Lower abdomen pain and irritative symptoms subsides after removal of catheter. None of the patient developed vesico-uterine fistula or any other complications.

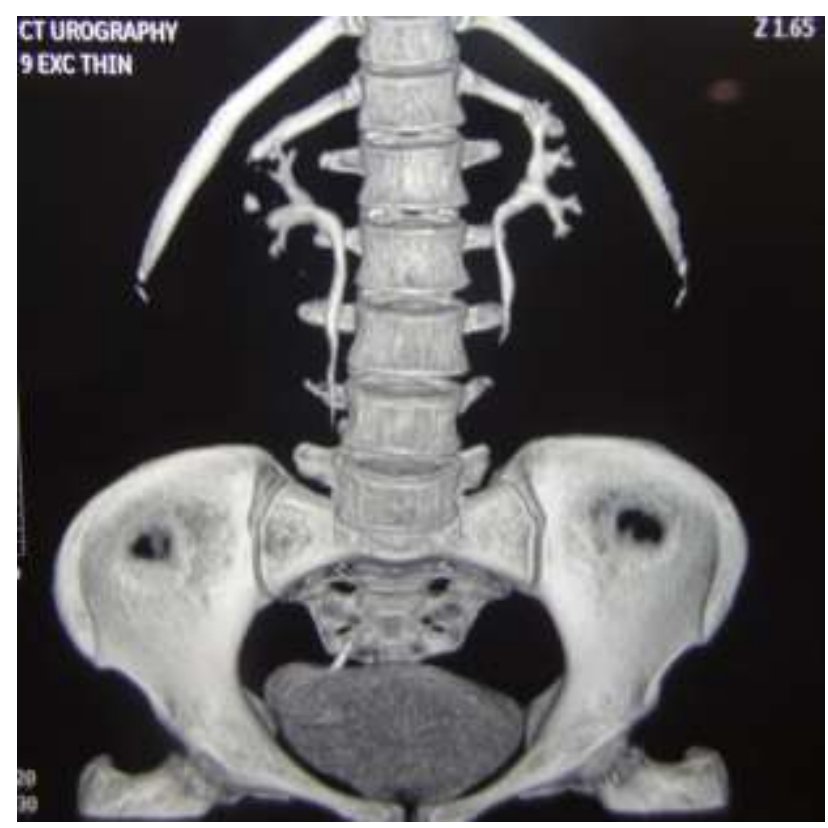

Figure 1: Computed Tomography image of the intrauterine contraceptive device embedded inside detrusor muscle of bladder.

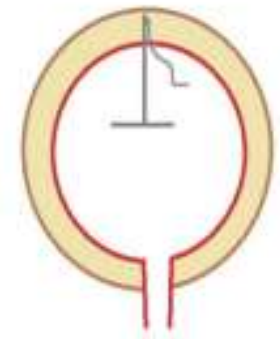

Case One

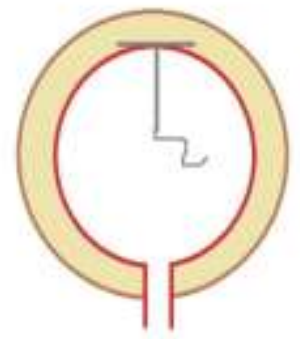

Case Two
Figure 2: Graphical representation of intrauterine contraceptive device embedded inside detrusor muscle of urinary bladder.

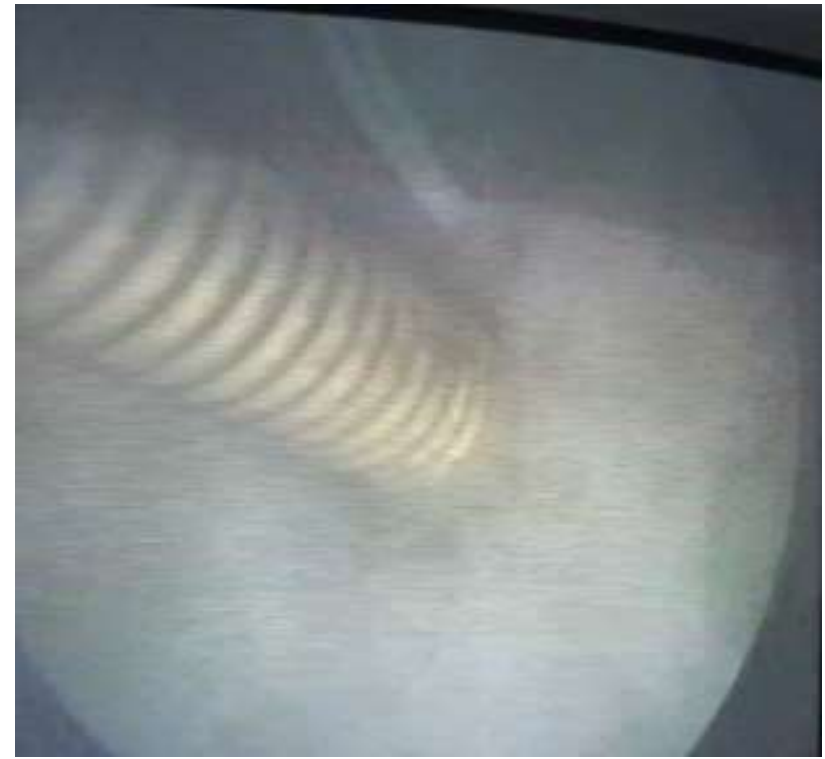

Figure: 3 Cystoscopic view of intrauterine contraceptive device embedded into detrusor muscle.

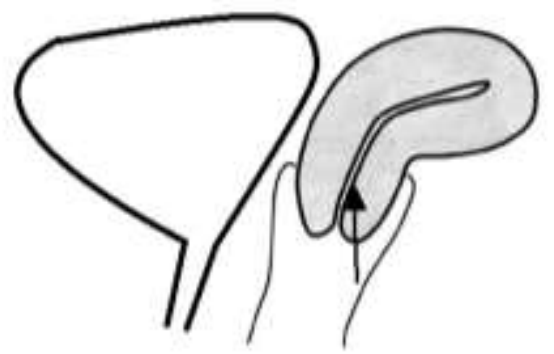

Figure 4: Direction of intrauterine contraceptive device insertion in retroverted uterus.

\section{DISCUSSION}

IUD is one of the popular methods of reversible contraception. But it is associated with rare complications such as uterine perforation and migration of IUD. Mechanism of uterine perforation may be primary at time of insertion; undetected extreme posterior uterine position is most common reason for perforation. ${ }^{4}$ Figure 4 is showing direction of IUD insertion in retroverted uterus in which there will be chances of migration into bladder. Risk of perforation also increases during puerperium ${ }^{5}$ and during menstruation where uterus is thin predisposing IUD migration. Chances also increase in multiparity, recent abortion, pregnancy or cesarean section. Secondary perforation of uterus can occur by slow migration of IUD which can be migrated into pelvis, intestine and urinary bladder. This secondary migration is augmented by spontaneous uterine contraction and bladder contractions. 
In our study recent onset of lower urinary tract symptoms suggest secondary perforation by slow migration of IUD. In both the patients thread was seen on follow up, hence suggestive of secondary perforation. Pregnancy in migrated IUD is well documented ${ }^{6}$ and none of our patient became pregnant after putting IUD. Migrated IUD into bladder should be suspected in cases of recent onset of lower abdominal pain associated with lower urinary tract symptoms which are not amenable to standard treatment. Migrated IUD in bladder can be easily diagnosed with abdomen ultrasonography (USG) and should be first investigation in suspected cases. Routine USG after insertion of IUD in all patients is not done but if thread is not seen in follow up then USG should be done. If any doubts about partial migration of IUD in bladder the CT cystogram should be done.
There are various methods of removal of migrated IUD in bladder like exploratory laparotomy, ${ }^{7}$ endoscopic removal. In our study both patients were successfully managed by endoscopic approach which is similar to other studies. ${ }^{4}$ Even if IUD arm is embedded into bladder muscle, endoscopic approach should be considered even though there are chances of mucosal and detrusor injury. There is always a theoretical chance of vesico-uterine fistula but none of our patients develop fistula. This can be explained by slow migration of IUD with spontaneous healing at uterus. Also in second patient only mucosal cuts were taken leaving detrusor muscle intact. When stones are formed over IUD, stones should be fragmented by litholapexy or intracorporeal lithotripsy. Exploratory and open bladder removal of IUD should only be considered in cases of large stones over IUD which is difficult to be managed by endoscopic route.

Table 1: Showing patient's characteristic and treatment given.

\begin{tabular}{|l|l|l|}
\hline Age ( Years ) & 26 & 32 \\
\hline $\begin{array}{l}\text { History of IUD insertion } \\
\text { (Years) }\end{array}$ & 1 year post menstrual & 2 at post menstrual \\
\hline Pregnancy after putting IUD & No & No \\
\hline Previous obstetrics history & 2 Vaginal delivery & 2 Vaginal delivery \\
\hline Symptoms duration & 3 months & 5 months \\
\hline Symptoms & Lower abdominal pain, Frequency & $\begin{array}{l}\text { Lower abdominal pain, Frequency, } \\
\text { Dysuria }\end{array}$ \\
\hline Associated bladder stone & No & No \\
\hline Intra Operative cystoscopy findings & $\begin{array}{l}\text { Vertical arm of IUD embedded in } \\
\text { detrusor muscle. } \\
\text { On removal detrusor and bladder } \\
\text { mucosal injury present }\end{array}$ & $\begin{array}{l}\text { Vertical arm was in the bladder and both } \\
\text { horizontal arms were embedded into } \\
\text { detrusor muscle. } \\
\text { On removal detrusor and bladder mucosal } \\
\text { injury present }\end{array}$ \\
\hline Intra operative maneuver & $\begin{array}{l}\text { With help of stone holding forceps, } \\
\text { IUD was pulled inside bladder and } \\
\text { removed intact. }\end{array}$ & $\begin{array}{l}\text { Colloscopy followed by with the help of } \\
\text { at junction of IUD and with help of stone } \\
\text { holding forceps; IUD was pulled inside } \\
\text { bladder and removed intact. }\end{array}$ \\
\hline Post-operative per urethral catheter & 14 days & days \\
\hline \hline Post-operative complication & No & No \\
\hline
\end{tabular}

\section{CONCLUSIONS}

Migrated IUD in bladder should be suspected in cases of recent onset of lower abdominal pain associated with lower urinary tract symptoms which are not amenable to standard treatment. USG should be first investigation for diagnosis. Endoscopic management of migrated IUD into urinary bladder is preferred mode of treatment even in cases of IUD embedded into detrusor muscle, thus endoscopic treatment is feasible and safe option over open surgery with minimal theoretical risk of fistula formation.

Funding: No funding sources Conflict of interest: None declared
Ethical approval: Not required

\section{REFERENCES}

1. http://www.un.org/en/development/desa/population/ publications/family/contraceptive-wallchart2013.shtml. Assessed 15 September 2015.

2. Caliskan E, Ozturk N, Dilbaz BO. Analysis of risk factors associated with uterine perforation by intrauterine devices. Eur J Contracept Reprod Health Care. 2003;8:150-5.

3. Van Houdenhoven K, van Kaam KJ, van Grootheest AC, Salemans TH, Dunselman GA. Uterine perforation in women using a levonorgestrel- 
releasing intrauterine system. Contraception. 2006;73(3):257-60.

4. Sallami Sataa, Ben Rhouma Sami, Rebai Sabeur, Cherif Karim, Horchani Ali. Bladder Calculus Resulting from the Migration of an Intrauterine Contraceptive Device: A Report of Ten Cases Int J Nephrol Urol. 2011;3(1):54-61.

5. Caliskan E, Oztürk N, Dilbaz BO, Dilbaz S. Analysis of risk factors associated with uterine perforation by intrauterine devices. Eur J Contracept Reprod Health Care. 2003;8(3):150-5.

6. Tosun M, Celik H, Yavuz E, Çetinkaya MB. Intravesical migration of an intrauterine device detected in a pregnant woman. Canadian Urological Association Journal. 2010;4(5):E141-E143.

7. Kurdoglu Z, Ceylan K, Kurdoglu M, Guler A, Sahin HG. Ectopic intrauterine device in the bladder of a pregnant woman. Case Rep Med. 2010; 2010.pii:181032.

Cite this article as: Sawant A, Kasat GV, Kumar V, Pawar P, Tamhankar A, Kapadnis L. Endoscopic removal of intrauterine contraceptive device embedded into detrusor muscle of urinary bladder: our experience of two cases. Int J Reprod Contracept Obstet Gynecol 2015;4:2096-9. 